04

\title{
Подвижность ионных носителей заряда в пьезоэлектрических кристаллах $\mathrm{Li}_{2} \mathrm{~B}_{4} \mathrm{O}_{7}$
}

\author{
(С) Н.И. Сорокин, Ю.В. Писаревский, В.В. Гребенев, В.А. Ломонов \\ Институт кристаллографии им. А.В. Шубникова ФНИЦ „Кристаллография и фотоника“ РАН, \\ Москва, Россия \\ E-mail: nsorokin1@yandex.ru
}

Поступила в Редакцию 19 октября 2019 г.

В окончательной редакции 19 октября 2019 г.

Принята к публикации 19 октября 2019 г.

Выполнены импедансные измерения монокристалла $\mathrm{Li}_{2} \mathrm{~B}_{4} \mathrm{O}_{7}$ с $\mathrm{Ag}$-электродами в интервале частот $1-3 \cdot 10^{7} \mathrm{~Hz}$ при комнатной температуре. Кристалл $\mathrm{Li}_{2} \mathrm{~B}_{4} \mathrm{O}_{7}$ (пр. гр $I 4_{1} c d, Z=8$ ) ориентировался вдоль кристаллографической оси $c$. Из годографа импеданса системы $\mathrm{Ag}\left|\mathrm{Li}_{2} \mathrm{~B}_{4} \mathrm{O}_{7}\right| \mathrm{Ag}$ выделены вклады от объема кристалла и границы кристалл/электрод. Обсуждается структурный механизм литийионного транспорта в кристаллах $\mathrm{Li}_{2} \mathrm{~B}_{4} \mathrm{O}_{7}$. На основании электрофизических и структурных данных рассчитаны сквозная проводимость $\sigma_{d c}=2.3 \cdot 10^{-9} \mathrm{~S} / \mathrm{cm}$, подвижность носителей заряда (вакансий $V_{\mathrm{Li}}^{-}$) $\mu_{m o b}=6 \cdot 10^{-10} \mathrm{~cm}^{2} / \mathrm{sV}$ и их концентрация $n_{m o b}=2.4 \cdot 10^{19} \mathrm{~cm}^{-3}(0.14 \%$ от количества лития в кристаллической решетке).

Ключевые слова:ионная проводимость, тетраборат лития, монокристаллы, импедансная спектроскопия.

DOI: 10.21883/FTT.2020.03.49001.631

\section{1. Введение}

Кристаллы тетрабората лития $\mathrm{Li}_{2} \mathrm{~B}_{4} \mathrm{O}_{7}$ (пр. гр $I 4_{1} c d$, $Z=8)$ являются перспективными материалами пьезотехники и акустоэлектроники, инфракрасной и нелинейной оптики; их дефектная структура и физические свойства интенсивно исследуются [1-8]. Монокристаллы $\mathrm{Li}_{2} \mathrm{~B}_{4} \mathrm{O}_{7}$ выращивают из расплава методом Чохральского $[4,6]$ или гидротермальным синтезом [9]. Обнаружено [9-15], что они обладают одномерной ионной $\left(\mathrm{Li}^{+}\right)$ проводимостью вдоль полярной кристаллографической оси $c$. В работах [9-15] ионная проводимость тетрабората лития измерялась как интегральная характеристика носителей заряда. Для микроскопического описания механизма ионной проводимости кристаллов $\mathrm{Li}_{2} \mathrm{~B}_{4} \mathrm{O}_{7}$ необходимо определить среднюю частоту перескоков $v_{h}$, выполнить расчет подвижности $\mu_{m o b}$ и концентрации $n_{m o b}$ ионных носителей.

Целью работы является рассмотрение кристаллофизической модели ионного переноса в $\mathrm{Li}_{2} \mathrm{~B}_{4} \mathrm{O}_{7}$ и расчет микроскопических характеристик носителей заряда. Предварительные результаты исследования были доложены на международном совещании „Фундаментальные проблемы ионики твердого тела“ (2018) [16].

\section{2. Эксперимент}

Кристаллы $\mathrm{Li}_{2} \mathrm{~B}_{4} \mathrm{O}_{7}$ выращены из расплава по методу Чохральского в Институте кристаллографии ФНИЦ „Кристаллография и фотоника“ РАН. Параметры тетрагональной элементарной ячейки равны $a=9.479$ и $c=10.286 \AA$. Плоскопараллельный образец толщиной
$0.5 \mathrm{~mm}$ и площадью $110 \mathrm{~mm}^{2}$ ориентировался вдоль полярной кристаллографической оси $c$ (Z-срез).

Электрофизические измерения проведены методом импедансной спектроскопии в диапазон частоты $(1-3) \cdot 10^{7} \mathrm{~Hz}$ (установка Novoterm-1200 с анализатором импеданса Alpha-AN) при комнатной температуре $(293 \mathrm{~K})$. Электроды выполнены в виде контактов Ag толщиной $70 \mathrm{~nm} \mathrm{c}$ адгезионным подслоем $\mathrm{Cr}$ толщиной $30 \mathrm{~nm}$.

Годограф удельного импеданса (комплексного сопротивления) $Z^{*}(v)$ для электрохимической системы $\mathrm{Ag}|\mathrm{Li} 2 \mathrm{~B} 4 \mathrm{O} 7| \mathrm{Ag}$ показан на рис. 1. На низких частотах наблюдается полуокружность с центром на оси абсцисс, при высоких частотах — наклонная прямая. Соответствующая годографу $Z^{*}(v)$ эквивалентная электрическая схема монокристалла $\mathrm{Li}_{2} \mathrm{~B}_{4} \mathrm{O}_{7}$ с блокирующими $(\mathrm{Ag})$ электродами представлена на вставке к рис. 1. Она содержит объемное сопротивление $R_{b}$, геометрическую емкость $C_{g}$ и частотно-зависимый элемент с постоянным фазовым углом $P_{e l}(\omega)$, отвечающий приэлектродным процессам накопления и переноса заряда на границах кристалл/электрод.

Параметры эквивалентной схемы определяли нелинейным методом наименьших квадратов, используя программу ZView (Scribner Associates). Удельное объемное сопротивление и геометрическая емкость равны $R_{b}=(4.34 \pm 0.05) \cdot 10^{8} \mathrm{Ohm}^{-1} \cdot \mathrm{cm}^{-1}$ и $C_{g}=(1.16 \pm 0.03) \cdot 10^{-12} \mathrm{~F} \cdot \mathrm{cm}^{-1}$ соответственно. Адмиттанс частотно-зависимого элемента $P_{e l}(\omega)$ имеет вид

$$
Y_{e l}^{*}=Y_{0}(i \omega)^{n},
$$

где $0 \leq n \leq 1$. В общем виде при $n=1$ элемент $P_{e l}(\omega)$ трансформируется в емкость $C, Y^{*}=C(i \omega)$; 


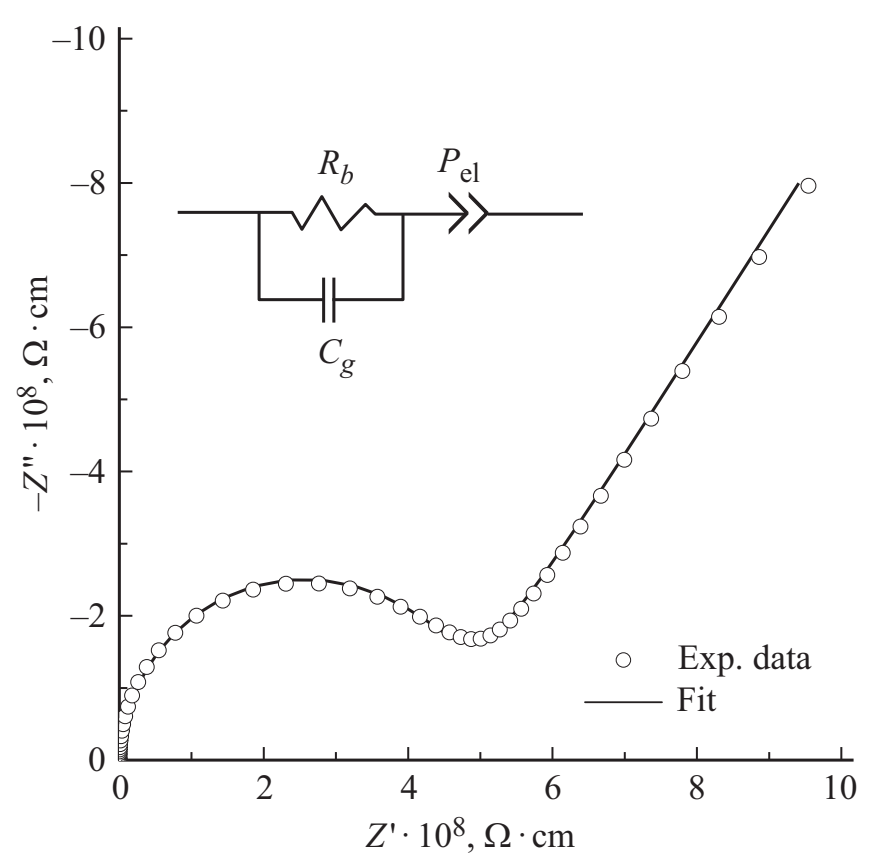

Рис. 1. Годограф импеданса $Z^{*}(v)$ и эквивалентная электрическая схема для системы $\mathrm{Ag}\left|\mathrm{Li}_{2} \mathrm{~B}_{4} \mathrm{O}_{7}\right| \mathrm{Ag}$.

при $n=0.5-$ в диффузионный импеданс Варбурга $W, Y^{*}=W(i \omega)^{0.5}$; при $n=0$ в активное сопротивление электродной реакции $R, Y^{*}=R^{-1}$. Рассчитанные параметры электродного импеданса $Y_{e l}^{*}$ составляют $Y_{e l, 0}=(2.35 \pm 0.04) \cdot 10^{-10} \mathrm{~S} \cdot \mathrm{cm}^{-1} \cdot \mathrm{Hz}^{0.64}$, $n_{e l} \approx 0.64 \pm 0.01$.

\section{3. Структурный механизм литийионного транспорта}

Особенности кристаллохимического строения кристаллов $\mathrm{Li}_{2} \mathrm{~B}_{4} \mathrm{O}_{7}$ указывают на анизотропный (одномерный) характер $\sigma_{d c}$, обусловленный преимущественной миграцией катионов $\mathrm{Li}^{+}$вдоль оси $c$ в каналах бор-кислородного каркаса. В основе кристаллической структуры $\mathrm{Li}_{2} \mathrm{~B}_{4} \mathrm{O}_{7}$ (пр. гр. $I 4_{1} c d, Z=8$ ) [1-3] лежит бор-кислородный каркас из комплексов $\left[\mathrm{B}_{2} \mathrm{O}_{9}\right]$, образованный двумя $\left[\mathrm{BO}_{4}\right]$-тетраэдрами и двумя планарными тригональными $\left[\mathrm{BO}_{3}\right]$-группами. Группа $\left[\mathrm{B}_{2} \mathrm{O}_{9}\right]$ изогнута и не имеет плоскости симметрии. Катионы бора расположены в характерных для этого элемента координационных полиэдрах двух типов: треугольниках $\left[\mathrm{BO}_{3}\right]$ и тетраэдрах $\left[\mathrm{BO}_{4}\right]$. Спектры $\mathrm{B}^{11}$ ЯМР [6] указывают на „жескость“ бор-кислородного каркаса, характер связей В-О является существенно ковалентным.

В элементарной ячейке тетрабората лития содержится 16 катионов $\mathrm{Li}^{+}$, расположенных в структурных каналах, которые простираются в направлении параллельно полярной оси $c$. Ионы $\mathrm{Li}^{+}$слабо связаны с бор-кислородным каркасом и их амплитуда тепловых колебаний в 2-5 раза больше, чем для „каркасных“ ионов $\mathrm{B}^{3+}$ и $\mathrm{O}^{2-}[2,3,14]$. Принято считать [9], что в кристаллах $\mathrm{Li}_{2} \mathrm{~B}_{4} \mathrm{O}_{7}$ в области собственной проводимости точечными дефектами, рождающимися в кристаллической решетке за счет тепловой энергии, являются дефекты по Френкелю, которые образуются в литиевой подрешетке.

Кристаллохимическое строение кристаллов $\mathrm{Li}_{2} \mathrm{~B}_{4} \mathrm{O}_{7}$ и величина энтальпии активации ионного транспорта $(0.4-0.5$ эВ $[11,12,17])$ указывают, что в условиях тепловой активации подвижные ионы $\mathrm{Li}^{+}$в ионном переносе участвуют по вакансионному механизму электропроводности. Структурные исследования кристаллов $\mathrm{Li}_{2} \mathrm{~B}_{4} \mathrm{O}_{7}$ [1-3] не зафиксировали недозаселенность позиций лития пр.гр. $I 4_{1} c d$, поэтому дефицит лития в кристаллографических позициях (число вакансий $V_{\mathrm{Li}}^{-}$) незначителен. Вакансии $V_{\mathrm{Li}}^{-}$возникают при росте кристаллов $\mathrm{Li}_{2} \mathrm{~B}_{4} \mathrm{O}_{7}$ и определяют их величину проводимости $\sigma_{d c}$.

\section{4. Подвижность и концентрация носителей заряда}

Носителями заряда прыжкового типа являются вакансии $V_{\mathrm{Li}}^{-}$, расположенные в кристаллографических позициях литиевой подрешетки. Это позволяет с учетом электрофизических и кристаллохимических данных для кристаллов $\mathrm{Li}_{2} \mathrm{~B}_{4} \mathrm{O}_{7}$ рассчитать подвижность $\mu_{m o b}$ и концентрацию $n_{m o b}$ носителей заряда.

Частотная зависимость динамической (переменнотоковой) проводимости $\sigma(v)$ для монокристалла $\mathrm{Li}_{2} \mathrm{~B}_{4} \mathrm{O}_{7}$ показана на рис. 2. Обработку частотной зависимости электропроводности проводили в рамках модели Алмонда-Веста [18]. Среднюю частоту прыжков $v_{h}$ носителей заряда определяли из зависимости динамической

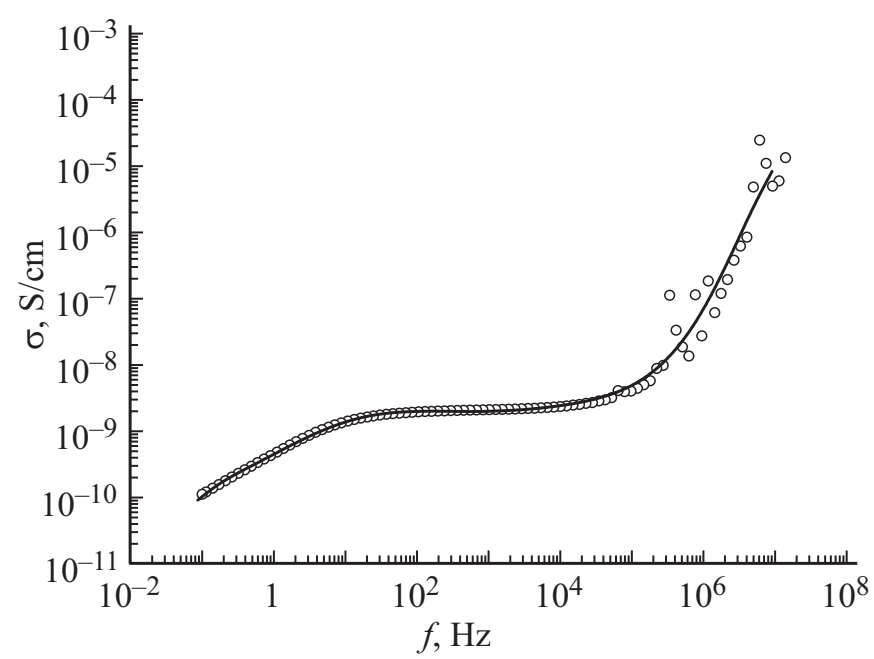

Рис. 2. Частотная зависимость проводимости $\sigma(v)$ для монокристалла $\mathrm{Li}_{2} \mathrm{~B}_{4} \mathrm{O}_{7}$. 
проводимости:

$$
\sigma(v)=\sigma_{d c}\left[1+\left(v / v_{h}\right)^{n}\right]
$$

где $\sigma_{d c}-$ статическая электропроводность. При $v<v_{h}$ ионные носители участвуют в процессе электропроводности, а при $v>v_{h}-$ в процессе диэлектрической релаксации. Из частотной зависимости проводимости $\sigma(v)$ найдены статическая проводимость $\sigma_{d c}=2.3 \cdot 10^{-9} \mathrm{~S} / \mathrm{cm}$ и частота прыжков носителей заряда $v_{h} \approx 1 \cdot 10^{5} \mathrm{~Hz}$.

Проведенная нами оценка из данных [15] электронной проводимости образцов $\mathrm{Li}_{2} \mathrm{~B}_{4} \mathrm{O}_{7}$, выращенных в тех же условиях в Институте кристаллографии, дала $\sigma_{e} \approx 2 \cdot 10^{-11} \mathrm{~S} / \mathrm{cm}$. Кондуктометрические измерения в [15] проводились на образцах с блокирующими (серебряными) электродами при наложении постоянного электрического поля 20-360 V/mm. В этом случае в стационарном режиме ионный ток через кристалл не течет, и остаточный ток определяется электронной составляющей $\sigma_{e}$. Полученные результаты указывают, что величина $\sigma_{e}$ не превышает $1 \%$ от общей электропроводности $\sigma_{d c}$ и определенная из импедансных измерений статическая проводимость $\sigma_{d c}$ имеет ионную природу.

Величина подвижности $\mu_{m o b}$ носителей заряда задается соотношением Нернста-Эйнштейна и определяется их частотой прыжков $v_{h}$ и длиной прыжка $d$ :

$$
\mu_{m o b}=q v_{h} d^{2} / 6 k T
$$

где $q-$ заряд, $T$ - температура. Среднее расстояние $\mathrm{Li}-\mathrm{Li}$ в кристаллической решетке $\mathrm{Li}_{2} \mathrm{~B}_{4} \mathrm{O}_{7}$ равно $d \approx 3 \AA[2,3,17])$. Подставив в (2) частоту $v_{h}$ и длину прыжков $d$ носителей заряда, находим подвижность $\mu_{m o b}$ носителей заряда $\mu_{m o b}=6 \cdot 10^{-10} \mathrm{~cm}^{2} / \mathrm{Vs}$. Полученное значение подвижности носителей заряда в кристалле $\mathrm{Li}_{2} \mathrm{~B}_{4} \mathrm{O}_{7}$ существенно ниже подвижности ионов $\mathrm{Li}^{+}$ $\mu_{m o b}=8 \cdot 10^{-7} \mathrm{~cm}^{2} / \mathrm{Vs}[19]$ в суперионном кристалле $\mathrm{Li}_{3 x} \mathrm{La}_{1 / 3-x} \mathrm{TaO}_{3}(x=0.06)$ со структурой перовскита.

Величина ионной проводимости кристаллов определяется произведением концентрации и подвижности носителей заряда

$$
\sigma_{d c}=q n_{m o b} \mu_{m o b}
$$

где $q-$ заряд, $n_{m o b}$ и $\mu_{m o b}-$ концентрация и подвижность соответственно. Взяв проводимость $\sigma_{d c}$ и подвижность $\mu_{m o b}$ носителей заряда, из (3) можно оценить концентрацию $n_{m o b}$ носителей заряда (вакансий $\left.V_{\mathrm{Li}}^{-}\right)$. Концентрация $n_{m o b}$ в изученном кристалле $\mathrm{Li}_{2} \mathrm{~B}_{4} \mathrm{O}_{7}$ равна

$$
n_{m o b}=\sigma_{d c} / q \mu_{m o b}=2.4 \cdot 10^{19} \mathrm{~cm}^{-3} .
$$

Расчет количества ионов $\mathrm{Li}^{+}$в кристаллической структуре $\mathrm{Li}_{2} \mathrm{~B}_{4} \mathrm{O}_{7}$ дает

$$
n_{\mathrm{Li}}=2 Z / a^{2} c=1.7 \cdot 10^{22} \mathrm{~cm}^{3},
$$

где число структурных единиц в элементарной ячейке $Z=8$. Величина носителей заряда nmob составляет $0.14 \%$ от количества ионов $\mathrm{Li}^{+}$в структуре $\mathrm{Li}_{2} \mathrm{~B}_{4} \mathrm{O}_{7}$.

\section{5. Заключение}

Методом импедансной спектроскопии измерена частотной зависимость проводимости $\sigma(v)$ кристаллов $\mathrm{Li}_{2} \mathrm{~B}_{4} \mathrm{O}_{7} \quad(\|$ оси $c)$, из которой в рамках подхода Алмонда-Веста найдены статическая проводимость $\sigma_{d c}=2.3 \cdot 10^{-9} \mathrm{~S} / \mathrm{cm}$ и частота прыжков носителей заряда $v_{h}=1 \cdot 10^{5} \mathrm{~Hz}$. Ионная проводимость $\sigma_{d c}$ кристаллов $\mathrm{Li}_{2} \mathrm{~B}_{4} \mathrm{O}_{7}$ обусловлена появлением подвижных катионов $\mathrm{Li}^{+}$вследствие структурного (позиционного) разупорядочения литиевой подрешетки. Ионный транспорт происходит прыжковыми перемещениями вакансий лития $V_{\mathrm{Li}}^{-}$по кристаллической решетке. Рассчитаны подвижность и концентрация носителей заряда, которые составляют $\mu_{m o b}=6 \cdot 10^{-10} \mathrm{~cm}^{2} / \mathrm{sV}$ и $n_{m o b}=2.4 \cdot 10^{19} \mathrm{~cm}^{-3}$.

\section{Финансирование работы}

Работа выполнена при поддержке Министерства науки и высшего образования в рамках выполнения работ по Государственному заданию ФНИЦ „Кристаллография и фотоника" РАН.

\section{Конфликт интересов}

Авторы заявляют, что у них нет конфликта интересов.

\section{Список литературы}

[1] J. Krog-Moe. Acta Cryst. 15, 190 (1962).

[2] J. Krog-Moe. Acta Cryst. B. 24, 179 (1968).

[3] С.Ф. Радаев, Л.А. Мурадян, Л.Ф. Малахова, Я.В. Бурак, В.И. Симонов. Кристаллография 34, 1400 (1989).

[4] И.М. Сильвестрова, П.А. Сенющенков, В.А. Ломонов, Ю.В. Писаревский. ФТТ 31, 311 (1989).

[5] А.Э. Алиев, Я.В. Бурак, В.В. Воробьев, И.Т. Лысейко, Е.А. Чарная. ФТТ 32, 2826 (1990).

[6] Ю.Н. Иванов, Я.В. Бурак, К.С. Александров. ФТТ 32, 3379 (1990).

[7] А.В. Вдовин, В.Н. Моисеенко, В.С. Горелик, Я.В. Бурак. ФTT 43, 1584 (2001)

[8] А.Э. Алиев, В.Ф. Криворотов, П.К. Хабибуллаев. ФТТ 39, 1548 (1997)

[9] D.R. Button, L.S. Masson, H.L. Tuller, D.R. Uhlmann. Solid State Ionics 9-10, 585 (1983).

[10] K. Byrappa, V. Rajeev, V.J. Hanumesh, A.R. Kulkarni, A.B. Kulkarni. J. Mater. Res. 11, 2616 (1996).

[11] А.Э. Алиев, Я.В. Бурак, И.Т. Лысейко. Изв. АН СССР. Неорган. материалы 26, 1991 (1990)

[12] A.F. Aliev, I.N. Kholmanov, P.K. Khabibullaev. Solid State Ionics. 118, 111 (1999).

[13] V.M. Rizak, I.M. Rizak, N.D. Bause, V.S. Bilanych, S.Yu. Stefanovych, M.B. Bohuslavskii, V.M. Holovey. Ferroelectrics 286, 49 (2003).

[14] S.J. Kim, W.K. Kim, Y.C. Cho, S. Park, I.K. Jeong, Y.S. Yang, Y. Kuroiwa, C. Moriyoshi, H. Tanaka, M. Takata, S.Y. Jeong. Current Appl. Phys. 11, 649 (2011). 
[15] А.Г. Куликов, Ю.В. Писаревский, А.Е. Благов, Н.В. Марченков, В.А. Ломонов, А.А. Петренко, М.В. Ковальчук. ФТТ 61, 671 (2019)

[16] Н.И. Сорокин, Ю.В. Писаревский, В.В. Гребенев, В.А. Ломонов. Tp. XIV междунар. совещания „Фундаментальные проблемы ионики твердого тела“. Черноголовка (9-13 сентября 2018). Издательская группа „Граница“, М. (2018). C. 115.

[17] M.M. Islam, T. Bredow, C. Minot. J. Phys. Chem. B 110, 17518 (2006).

[18] D.P. Almond, C.C. Hunter, A.R. West. J. Mater. Sci. 19, 3236 (1984).

[19] K. Mizumoto, S. Hayashi. J. Ceram. Soc. Jpn. 106, 713 (1998).

Редактор Т.Н. Василевская 